\title{
Environmental Factors on Concept Maps Design
}

\author{
Daniela Oliveira $^{1}$, Mickael Gardoni ${ }^{1}$, Kimiz Dalkir $^{2}$ \\ ${ }^{1}$ École de Technologie Supérieure, Montreal, Canada \\ ${ }^{2}$ School of Information Studies, McGill University, Montreal, Canada \\ daniela.oliveira@mcgill.ca
}

\begin{abstract}
Building Information Modeling (BIM) environments have a lot of potential to facilitate communication and support collective work, speeding construction times and increasing the overall quality of the project. A few ontologies creation efforts have been made by both academia and practitioners to foster the transmission of knowledge in BIM environments. This paper aims to add to the discussion by analyzing the notes of users of concept maps, knowledge structures similar to ontologies, and comparing them to BIM environment researchers'.
\end{abstract}

Keywords: BIM·Concept Maps·Knowledge Management·Knowledge Transmission·Knowledge Construction·Ontologies

\section{Introduction}

Building Information Modeling (BIM) environments are excellent candidates for the implementation of Knowledge Management (KM) techniques and tools. As Dalkir [13] points out, one of the problems KM can help solve in projects being object to BIM is the need for professionals in different disciplines to "speak the same language". It seems that while technical interoperability surrounding BIM has been addressed by the development of standards and long-term use of BIM tools [22], business interoperability is yet to be fully supported in order to expand collaboration [33]. The multidisciplinary perspectives the same object can take in Architecture/Engineering/Construction (AEC) and the lack of tools that can support them seem to be in cause [30].

A bibliographic study of BIM literature has shown that in recent years ontologies have been considered as a means to foster collaboration in AEC environments exchanging BIM, but very few studies addressed different context or environmental elements in the interpretation process of ontologies [48]. This bibliographic investiga- 
tion has justified Cerovsek's [5] perception that little attention was being paid to the semiotics of communication in AEC. In other words, the AEC field lacks studies on BIM projects and the different meanings and interpretations the same object or object characteristics may take.

Variance of meaning, or semiotics, is a natural element of human communication. As people have different backgrounds, beliefs and experience, it is natural that they accord different meanings to the same words and symbols. While semiotics account for the cultural richness in society, in a performance-intensive environment, such as construction, it can be a source of misunderstandings, frustrations, and barriers to collective work.

\section{Concept Maps and Ontologies}

Concept maps are knowledge structures that codify objects and their relation to each other. Several perspectives are used to depict the various dimensions of a relationship between two objects. In educational settings, the process of creating a concept map helps students relate different concepts of the domain explored [14]. Once the concept map is ready, it serves as a tangible representation of the domain and helps the student recall the propositions of the domain [28]. In knowledge management, concept maps are used to produce "visual representations of complex knowledge domains that meet social scientists' standards for rigor and reliability, while being easily interpretable to practitioners" [40]. The collaborative design process of the concept map is itself a team-building activity and involves a lot of articulation and negotiation skills $[18,51]$. Concept maps' capacity to promote the construction of shared meaning assured the tool the recognition as a feminist research method [3]. Concept maps are the first step for the creation of ontologies $[2,4,50,60]$. Concept maps that conform to a specific format and are machine-readable are called Ontologies.

Ontologies have been developed and implemented in BIM projects to help increase knowledge flow and business interoperability. The Information Delivery Manuals (IDM), guiding BIM implementations, represent the effort to connect and describe the context [25]. They are intended to provide directives to represent what is the place of a process, what is its relevance, the actors around the information represented, the information itself and how it should be supported by applications [59]. However, as Eastman, one of the most prominent scholars studying BIM [61], argues, the use of IDM is only a first step towards answering the need for full interoperability in BIM tools [15].

\section{Environmental factors in $\mathrm{KM}$ and Education}

In November 2017, I (Daniela) felt the urge to reflect on the influence and power imbalances surrounding the creation of concept maps. I have engaged myself in an exercise of critical reflection [10] on my own experiences facilitating concept maps creation in Knowledge management (KM) and education settings for the past five years. The production and treatment of the content followed Trochim's [53] method 
adapted to one single participant and low-volume data. Fifty-nine statements related to environmental factors around the creation of concept maps were produced. These statements were regrouped in fourteen categories, which were then named. Similarities between the labels of categories motivated a subsequent fusion and reorganization of categories, resulting in the eleven main elements that motivated this study.

Previous research had already suggested that contextual factors may be responsible for mixed findings in concept maps studies [1]. In the preliminary phase of this study, validation in the literature was sought for these elements emerging from practice. These elements may have considerable impact on concept maps and, as a consequence, in ontologies creation and use. They have been divided into four categories, explained as follows.

\subsection{People involved}

Who creates the tool. Different people might produce different concept maps on the same subject [44].

In educational settings, concept maps may be created by the instructor or by the student [1], by a group of students having an instructor as a mediator and by a group of students working conjointly with an instructor. The number of participants representing knowledge influences the outcome of this representation [29]

In KM settings, concept maps may be designed by an information professional only, to express the results of document analysis, or in design sessions. Participants of design sessions tend to be admitted by invitation only [53]. The selection of participants usually takes into account their category [58] (external or internal client, subject matter expert, management level, for example); their potential to interact with other participants - power imbalances may be considered; their availability and their added value to the project. When conceiving how the concept map should be designed, the information professional considers what kind and level of endorsement would be most beneficial to the knowledge representation. The same participants may not take place in every step of the concept map production $[31,53]$.

The perception of the creators' authority in the field may represent a bias for the concept maps users, as would the creators' reputation and the support from senior management they are perceived to enjoy.

Importance of participants' knowledge and scope. How concept maps users and facilitators see the importance of the knowledge of the participants involved in the design of the concept map is likely to vary. In educational settings, students are less credited of understanding of the knowledge domain than are instructors. Students' knowledge representation in concept maps is perceived as the expression of their knowledge, rather than a representation tailored to meet users' needs. This common perception has to be taken into account by the facilitator when choosing intervention techniques. 
In situations where instructors have authored the concept map, the general perception is that a didactic reduction was made to adapt to novices' understanding, leaving important knowledge of the field unrepresented in the concept map.

In KM settings, the knowledge articulated either by participants or by the information professional alone is seen as the important knowledge in the field. The common perception is that a selection of the important concepts was made - and what was left out is not as important.

Who uses the tool. In educational settings, any student - being the concept map's author or not - may use concept maps produced by instructors or by students working with an instructor. Concept maps produced by one single student are usually only used by that single student.

The relationship between authors and users may create different user experiences. For instance, as mentioned, concept maps may perform the role of an individual's memory guide if they are both the sole author and user but will take the role of an exploration path if the author is the instructor and the user, a novice.

In KM settings, the number of users can largely outnumber the group of creators. Concept maps may be used by employees, clients, suppliers and government for regulation purposes, even if they have been authored by one single person. Concept maps authored by one single person may be used by a sole other person, for example, when expressing the reasoning used behind an algorithm or technical solution.

The target user population will certainly have its influence in the authoring process. Facilitators should take authors' view of the target population into account when planning for concept maps design sessions.

\subsection{Trends}

Purpose. In educational settings, concept maps may be used to portray a knowledge field to be explored, to serve as a guide to one's knowledge and to assess learning. The purpose of the concept map will certainly have an impact on how it is produced. A concept map created as a guide to the author's understanding and memory of the field will not be the same as one created to display the author's understanding of the field.

In KM settings, concept maps may be created to help specify the conceptual frameworks of programs $[45,54]$, to help attribute meaning to sets of data [23], to determine technological solutions requirements [17], or as an aid to navigate internal documents or content published on the organization's website [27], among other uses. When coupled with other tools, they may also be used to assess relevance of documents over time. The purpose for which the concept map was created suggests the point of evolution of the knowledge represented, or how much agreement exists in the field at that moment. In other words, the concept map portrays, in some way, the collective endorsement of the knowledge represented. 
Evaluation criteria. The purpose of the concept map may be attached to an evaluation strategy. Among other uses, evaluation strategies aim to assess the suitability of the concept map for the task it is intended to support or the coverage of its scope. Although there is still no acclaimed method for testing concept maps [57], it is reasonable to expect that evaluation criteria to be applied in a concept map influences the facilitator's choices of intervention techniques.

\subsection{The impact of time}

Number of workshops over time. Concept maps are usually produced in one session in educational settings, although they may be incremented over time. In KM settings, concept maps usually take one to five sessions to be considered final [53].

Momentum of production. As the concept map portrays the author's vision of the knowledge field at a specific point in time, a concept map produced in the beginning of a course or a project will be drastically different from one produced by the end of a course or project. The momentum of production may affect participant's motivation and user's perception of reliability of the tool.

Time of tool consumption. Concept maps are used in educational settings while the user considers the knowledge important and the tool useful, which could mean for the duration of a course or an educational program. In KM settings, concept maps may be used long time after production, especially when they serve as guides for navigating documents or content [27].

\subsection{Collaboration issues}

Facilitators and authors of concept maps will try to compensate for any perceived inadequacies regarding the preceding elements. For example, a facilitator conducting a concept design session in the beginning of a project for a concept map intended to hold a good level of maturity in concepts will stimulate participants to perform divergent thinking and will try to diversify interventions to achieve the desired level of maturity in concepts; a student might use shorter terms and clearer relationships when being evaluated through a concept map.

Variety. Focus groups, workshops, input from interviews [53] and document analysis [42], are some of the methods used to gather ideas for concept maps.

Collaboration. When concept maps are to be authored through collaboration, greater attention is given to staffing $[31,53]$. That may include stimuli for different learning styles [55] and assuring representativeness of all participants in the end product. 
Techniques for animation. Different techniques might be used to assure accurate representativeness of the participants in the end product. The idea is to have participants exploring different points of view and relationships [43] and being able to name concepts, ideas [19] and, more rarely but also importantly, emotions [7].

Table 1 summarizes the design process differences and the different factors involved.

Table 1. Main aspects and factors related to concept maps use in KM and Education

\begin{tabular}{|l|l|}
\hline Main aspect & Factor \\
\hline People & $\begin{array}{l}\text { Who creates the information; importance of participants' knowledge; who } \\
\text { uses the information; individual endorsement }\end{array}$ \\
\hline Trends & $\begin{array}{l}\text { Purpose - why was the information codified; evaluation criteria - how is the } \\
\text { information expected to be evaluated; collective endorsement }\end{array}$ \\
\hline Time & $\begin{array}{l}\text { Frequency of information generation; point in the process generating infor- } \\
\text { mation; point in the process where information is consumed }\end{array}$ \\
\hline Collaboration & $\begin{array}{l}\text { Criteria for selection of people to be involved; how interactive was the crea- } \\
\text { tion process; how did people interact when generating the information }\end{array}$ \\
\hline
\end{tabular}

\section{Ontologies perspectives in AEC}

Three very different perspectives in representing context were identified in the AEC. For Lee and Jeong [30], the people involved and the purpose of the information are the key elements to identify context in BIM projects. The authors describe a solution divided in a private and a public space. In the public space, the views of the objects depend on the qualification of the subject (e.g. an architect, a structural engineer and a mechanical engineer). For each object, the ontology would carry information describing the creator of the published data, the date of creation or modification, the qualifier of the relationships with other objects (e.g. a part of, a kind of) and "detailed description on reasons of creating or modifying the published data" [30].

The individual versus the shared space idea was originally explored by Cerovsek [5], who divides context description into various "standpoints". In the individual sphere, Resources, Process, Process result, BIM literacy and BIM tool would provide enough information for the evaluation of BIM support. In the shared space, the Reference Location, Time, Group, Teamwork, Business process, Information sharing, Application sharing and Communication channel would be the points helping evaluate BIM-enabled collaboration [5].

The framework conceived by Succar [52] identify fields, maturity and lenses / filters in a project. "Fields" relate to Technology, Process and Policy fields. "Maturity" aims to describe in much detail the point of the project where the object being described resides. "Lenses/Filters" present different views of the data. "Lenses" would 
present all the information that answer a specific criterion, while "Filters" would present all the information that does not answer the criterion.

Up to the submission of this paper, to our knowledge, no attempt to integrate these three perspectives was made. Although concern about contextual or environmental factors is present in AEC literature, the level of discussion seems to be considerably still too low to inform approaches in practice.

\section{Discussion}

Even though not much have been said about communication in BIM projects and its relation to ontology use $[5,48]$, some of the environmental factors identified in concept maps production and use were already identified in AEC literature. Environmental factors involved in the representation of knowledge in KM, Education and AEC can be summarized as follows:

Table 2. Environmental factors of concept maps and their acknowledgement in AEC literature

\begin{tabular}{|l|l|l|l|}
\hline Main aspect & Factor & KM/Education & In AEC \\
\hline People & $\begin{array}{l}\text { Who creates the information; importance of } \\
\text { participants' knowledge; who uses the infor- } \\
\text { mation; group; teamwork; individual endorse- } \\
\text { ment }\end{array}$ & $\mathrm{X}$ & {$[30]$ [5] } \\
\hline Trends & $\begin{array}{l}\text { Purpose - why was the information codified; } \\
\text { evaluation criteria - how is the information } \\
\text { expected to be evaluated; collective endorse- } \\
\text { ment }\end{array}$ & $\mathrm{X}$ & \\
\hline Time & $\begin{array}{l}\text { Frequency of information generation; point in } \\
\text { the process where information is generated; } \\
\text { date of creation or modification; point in the } \\
\text { process where information is consumed }\end{array}$ & $\mathrm{X}$ & [52], [30] \\
\hline Collaboration & $\begin{array}{l}\text { Criteria for selection of people to be involved; } \\
\text { how interactive was the creation process; how } \\
\text { did people interact when generating the infor- } \\
\text { mation; information sharing; application shar- } \\
\text { ing; communication channel }\end{array}$ & $\mathrm{X}$ & [5] \\
\hline
\end{tabular}

The identification of environmental factors of concept maps in AEC literature might indicate that research on the impact of these factors in ontology use would be welcomed in the AEC field. In practical terms, the correspondence suggests that there is a lot more to the process of knowledge building and consensus finding in BIM projects than the current ontology use supports. Therefore, BIM project managers and participants should be aware that BIM environments are not exempt from misconceptions and misunderstandings. Communication opportunities in a variety of channels should be encouraged to reduce conflicts having low positive impact in the construction process. 


\section{Conclusion}

The creation of a concept map does not limit itself to the consignation of propositions into nodes and lines. A series of actions in design planning impact the actual design of the concept map and might influence how the concept map is perceived and put into use. If the same reasoning is applied to ontologies related to BIM, the information consigned in the ontology should not limit itself to the description of objects, but also the context in which those objects were created. Insight from the interaction between people and the knowledge representation in concept maps suggest that ontologies should also address the process of consensus building.

Similarities and differences between KM, Education and AEC in the description of context were identified. These preliminary findings suggest the usefulness of a larger and empirical research study on the context of objects represented in BIM tools.

\section{Limitations}

As this study originated in a single practitioner's experience, it might not represent an exhaustive list of environmental factors impacting knowledge representation in ontologies. Empirical, multi-participant, larger studies on environmental factors are encouraged. The results from the equivalence of factors in KM and Education and in AEC literature have to be considered taking into account the scarcity of literature in the AEC field. Exploration of the topic by AEC is also encouraged.

\section{Acknowledgement}

Daniela's work was supported by McGill University's Centre for Social and Cultural Data Science (CSCDS) grant number J1317026.

\section{References}

1. Adesope OO, Nesbit JC (2009) A systematic review of research on collaborative learning with concept maps. In: Handbook of research on collaborative learning using concept mapping. Information Science Reference, Hershey, PA, pp 238-255

2. Brilhante V, Macedo G, Macedo S (2006) Heuristic transformation of wellconstructed conceptual maps into owl preliminary domain ontologies. In: Workshop on Ontologies and their Applications, WONTO

3. Campbell R, Salem DA (1999) Concept mapping as a feminist research method. Psychol Women Q 23:65-89. doi: https://doi.org/10.1111/j.1471-6402.1999.tb00342.x

4. Castro AG, Rocca-Serra P, Stevens R, Taylor C, Nashar K, Ragan MA, Sansone S-A (2006) The use of concept maps during knowledge elicitation in ontology development processes - the nutrigenomics use case. BMC Bioinformatics 7:267. doi: 10.1186/14712105-7-267

5. Cerovsek T (2011) A review and outlook for a "Building Information Model" (BIM): A multi-standpoint framework for technological development. Adv Eng Inform 25:224244. doi: 10.1016/j.aei.2010.06.003

7. Ci C, Choi S (2017) How to manage a city's image using the brand concept map and network analysis: a case of Seoul. Qual Quant 51:2441-2456. doi: 10.1007/s11135-0160402-6 
10. Daley, A (2010) Reflections on Reflexivity and Critical Reflection as Critical Research Practices. Affillia 25:68-82. doi: 10.1177/0886109909354981

13. Dalkir K (2017) A Knowledge Management Approach for Digital Cultural Heritage Preservation. Istanbul

14. Dansereau DF (2005) Node-Link Mapping Principles for Visualizing Knowledge and Information. In: Knowledge and Information Visualization. Springer, Berlin, Heidelberg, pp 61-81

15. Eastman C. M., Jeong Y.-S., Sacks R., Kaner I. (2010) Exchange Model and Exchange Object Concepts for Implementation of National BIM Standards. J Comput Civ Eng 24:25-34. doi: 10.1061/(ASCE)0887-3801(2010)24:1(25)

17. Freeman LA (2004) The Effects of Concept Maps on Requirements Elicitation and System Models During Information Systems Development. In: Cañas AJ, Novak JD, González F (eds) Concept Maps: Theory, Methodology, Technology. Proc. of the First Int. Conference on Concept Mapping. Universidad Pública de Navarra, Pamplona, Spain, pp 257-264

18. Freeman LA, Jessup LM (2004) The power and benefits of concept mapping: measuring use, usefulness, ease of use, and satisfaction. Int J Sci Educ 26:151-169. doi: 10.1080/0950069032000097361

19. González HL, Palencia AP, Umaña LA, Galindo L, Villafrade M LA (2008) Mediated learning experience and concept maps: a pedagogical tool for achieving meaningful learning in medical physiology students. Adv Physiol Educ 32:312-316. doi: 10.1152/advan.00021.2007

22. Howard R, Björk B-C (2008) Building information modelling - Experts' views on standardisation and industry deployment. Adv Eng Inform 22:271-280. doi: $10.1016 / j$.aei.2007.03.001

23. Jackson KM, Trochim WMK (2002) Concept Mapping as an Alternative Approach for the Analysis of Open-Ended Survey Responses. Organ Res Methods 5:307-336. doi: $10.1177 / 109442802237114$

25. Laakso M, Kiviniemi A (2012) THE IFC STANDARD - A REVIEW OF HISTORY, DEVELOPMENT, AND STANDARDIZATION. J Inf Technol Constr ITcon 17:134-161

27. Lambe P (2007) Organising knowledge: taxonomies, knowledge and organisational effectiveness. Chandos Publishing (Oxford) Ltd, Witney

28. Lambiotte JG, Dansereau DF, Cross DR, Reynolds SB (1989) Multirelational semantic maps. Educ Psychol Rev 1:331-367. doi: 10.1007/BF01320098

29. Larivière V, Gingras Y, Sugimoto CR, Tsou A (2015) Team size matters: Collaboration and scientific impact since 1900. J Assoc Inf Sci Technol 66:1323-1332. doi: 10.1002/asi.23266

30. Lee J, Jeong Y (2012) User-centric knowledge representations based on ontology for AEC design collaboration. Comput-Aided Des 44:735-748. doi: 10.1016/j.cad.2012.03.011

31. Linton R (1989) Conceptualizing feminism: Clarifying social science concepts. Eval Program Plann 12:25-29. doi: 10.1016/0149-7189(89)90018-9

33. Liu Y, Van Nederveen S, Hertogh M (2017) Understanding effects of BIM on collaborative design and construction: An empirical study in China. Int J Proj Manag 35:686698. doi: 10.1016/j.ijproman.2016.06.007

38. Novak JD (1990) Concept mapping: A useful tool for science education. J Res Sci Teach 27:937-949. doi: 10.1002/tea.3660271003 
42. Ridde V (2008) "The problem of the worst-off is dealt with after all other issues": The equity and health policy implementation gap in Burkina Faso. Soc Sci Med 66:13681378. doi: 10.1016/j.socscimed.2007.10.026

43. Rogers RR (2001) Reflection in Higher Education: A Concept Analysis. Innov High Educ 26:37-57. doi: 10.1023/A:1010986404527

44. Rosas SR (2017) Multi-map comparison for group concept mapping: an approach for examining conceptual congruence through spatial correspondence. Qual Quant 51:24212439. doi: $10.1007 / \mathrm{s} 11135-016-0399-\mathrm{x}$

45. Rosas SR, Camphausen LC (2007) The use of concept mapping for scale development and validation in evaluation. Eval Program Plann 30:125-135. doi: 10.1016/j.evalprogplan.2007.01.003

48. Santos R, Costa AA, Grilo A (2017) Bibliometric analysis and review of Building Information Modelling literature published between 2005 and 2015. Autom Constr 80:118136. doi: 10.1016/j.autcon.2017.03.005

49. Srinivasan M, McElvany M, Shay JM, Shavelson RJ, West DC (2008) Measuring Knowledge Structure: Reliability of Concept Mapping Assessment in Medical Education. Acad Med 83:1196. doi: 10.1097/ACM.0b013e31818c6e84

50. Starr RR, Oliveira JMP de (2013) Concept maps as the first step in an ontology construction method. Inf Syst 38:771-783. doi: 10.1016/j.is.2012.05.010

52. Succar B (2009) Building information modelling framework: A research and delivery foundation for industry stakeholders. Autom Constr 18:357-375. doi: 10.1016/j.autcon.2008.10.003

53. Trochim WM (1989) An introduction to concept mapping for planning and evaluation. Eval Program Plann 12:1-16. doi: https://doi.org/10.1016/0149-7189(89)90016-5

54. Trochim WM, Cook JA, Setze RJ (1994) Using concept mapping to develop a conceptual framework of staff's views of a supported employment program for individuals with severe mental illness. J Consult Clin Psychol 62:766

55. Vincent A, Ross D (2001) Personalize training: determine learning styles, personality types and multiple intelligences online. Learn Organ 8:36-43. doi: $10.1108 / 09696470110366525$

57. Weinerth K, Koenig V, Brunner M, Martin R (2014) Concept maps: A useful and usable tool for computer-based knowledge assessment? A literature review with a focus on usability. Comput Educ 78:201-209. doi: 10.1016/j.compedu.2014.06.002

58. Windsor LC (2013) Using Concept Mapping in Community-Based Participatory Research: A Mixed Methods Approach. J Mix Methods Res 7:274-293. doi: 10.1177/1558689813479175

59. Wix J, Karlshoej J (2010) Information delivery manual: Guide to components and development methods. Build Int 5:10

60. Yao J, Gu M (2013) Conceptology: Using Concept Map for Knowledge Representation and Ontology Construction. J Netw 8:1708-1712

61. Zhao X (2017) A scientometric review of global BIM research: Analysis and visualization. Autom Constr 80:37-47. doi: 10.1016/j.autcon.2017.04.002 